Old Dominion University

ODU Digital Commons

Biological Sciences Faculty Publications

Biological Sciences

2017

\title{
Fit to Predict? Ecoinformatics for Predicting the Catchability of a Pelagic Fish in Near Real-Time
}

Kylie L. Scales

Elliot L. Hazen

Sara M. Maxwell

Old Dominion University, smaxwell@odu.edu

Heidi Dewar

Suzanne Kohin

See next page for additional authors

Follow this and additional works at: https://digitalcommons.odu.edu/biology_fac_pubs

Part of the Aquaculture and Fisheries Commons, Biology Commons, and the Oceanography Commons

\section{Repository Citation}

Scales, Kylie L.; Hazen, Elliot L.; Maxwell, Sara M.; Dewar, Heidi; Kohin, Suzanne; Jacox, Michael G.; Edwards, Christopher A.; Briscoe, Dana K.; Crowder, Larry B.; Lewison, Rebecca L.; and Bograd, Steven J., "Fit to Predict? Ecoinformatics for Predicting the Catchability of a Pelagic Fish in Near Real-Time" (2017). Biological Sciences Faculty Publications. 219.

https://digitalcommons.odu.edu/biology_fac_pubs/219

\section{Original Publication Citation}

Scales, K. L., Hazen, E. L., Maxwell, S. M., Dewar, H., Kohin, S., Jacox, M. G., . . Bograd, S. J. (2017). Fit to predict? Ecoinformatics for predicting the catchability of a pelagic fish in near real-time. Ecological Applications, 27(7), 1-17. doi:10.1002/eap.1610 
Authors

Kylie L. Scales, Elliot L. Hazen, Sara M. Maxwell, Heidi Dewar, Suzanne Kohin, Michael G. Jacox, Christopher A. Edwards, Dana K. Briscoe, Larry B. Crowder, Rebecca L. Lewison, and Steven J. Bograd 


\title{
Fit to predict? Eco-informatics for predicting the catchability of a pelagic fish in near real time
}

\author{
Kylie L. Scales, ${ }^{1,2,3,8}$ Elliott L. Hazen,,${ }^{1,2}$ Sara M. Maxwell, ${ }^{4}$ Heidi Dewar,${ }^{5}$ Suzanne Kohin, ${ }^{5}$ \\ Michael G. Jacox, ${ }^{1,2}$ Christopher A. Edwards, ${ }^{1}$ Dana K. Briscoe,${ }^{6}$ Larry B. Crowder,${ }^{6}$ \\ Rebecca L. Lewison, ${ }^{7}$ and Steven J. Bograd ${ }^{2}$ \\ ${ }^{1}$ Institute of Marine Science, University of California Santa Cruz, Santa Cruz, California 95064 USA \\ ${ }^{2}$ Environmental Research Division, NOAA Southwest Fisheries Science Center, 99 Pacific Street, Suite \#255A, \\ Monterey, California 93940 USA \\ ${ }^{3}$ University of the Sunshine Coast, Maroochydore, Queensland 4556 Australia \\ ${ }^{4}$ Old Dominion University, 5115 Hampton Boulevard, Norfolk, Virginia 23529 USA \\ ${ }^{5}$ NOAA Southwest Fisheries Science Center, 8901 La Jolla Shores Drive, La Jolla, California 92037 USA \\ ${ }^{6}$ Hopkins Marine Station of Stanford University, 120 Ocean View Boulevard, Pacific Grove, California 93950 USA \\ ${ }^{7}$ San Diego State University, 5500 Campanile Drive, San Diego, California 92182 USA
}

\begin{abstract}
The ocean is a dynamic environment inhabited by a diverse array of highly migratory species, many of which are under direct exploitation in targeted fisheries. The timescales of variability in the marine realm coupled with the extreme mobility of ocean-wandering species such as tuna and billfish complicates fisheries management. Developing eco-informatics solutions that allow for near real-time prediction of the distributions of highly mobile marine species is an important step towards the maturation of dynamic ocean management and ecological forecasting. Using $25 \mathrm{yr}$ (1990-2014) of NOAA fisheries' observer data from the California drift gillnet fishery, we model relative probability of occurrence (presence-absence) and catchability (total catch per gillnet set) of broadbill swordfish Xiphias gladius in the California Current System. Using freely available environmental data sets and open source software, we explore the physical drivers of regional swordfish distribution. Comparing models built upon remotely sensed data sets with those built upon a data-assimilative configuration of the Regional Ocean Modelling System (ROMS), we explore trade-offs in model construction, and address how physical data can affect predictive performance and operational capacity. Swordfish catchability was found to be highest in deeper waters $(>1,500 \mathrm{~m})$ with surface temperatures in the $14-20^{\circ} \mathrm{C}$ range, isothermal layer depth (ILD) of $20-40 \mathrm{~m}$, positive sea surface height $(\mathrm{SSH})$ anomalies, and during the new moon $(<20 \%$ lunar illumination). We observed a greater influence of mesoscale variability ( $\mathrm{SSH}$, wind speed, isothermal layer depth, eddy kinetic energy) in driving swordfish catchability (total catch) than was evident in predicting the relative probability of presence (presence-absence), confirming the utility of generating spatiotemporally dynamic predictions. Data-assimilative ROMS circumvent the limitations of satellite remote sensing in providing physical data fields for species distribution models (e.g., cloud cover, variable resolution, subsurface data), and facilitate broad-scale prediction of dynamic species distributions in near real time.
\end{abstract}

Key words: dynamic ocean management; ecological forecasting; fisheries; ocean model; Regional Ocean Modelling System; remote sensing; satellite; species distribution model.

\section{INTRODUCTION}

In the age of data science, ecological informatics ("ecoinformatics") confers unprecedented opportunity to improve the management of natural resources across terrestrial and marine systems. Eco-informatics is an emerging interdisciplinary framework that seeks to generate new knowledge through innovative digital approaches to the generation, sampling, processing, analysis, visualization,

Manuscript received 30 September 2016; revised 24 May 2017; accepted 11 July 2017. Corresponding Editor: Andre Boustany.

${ }^{8}$ E-mail: kscales@usc.edu.au management, and dissemination of ecological, environmental, and socioeconomic data (Michener and Jones 2012). A key aspect is the development of practical tools to inform decision making and offer policy and management solutions to complex environmental problems.

In the marine environment, eco-informatics tools are currently in their infancy. Dynamic ocean management, an approach to the management of marine resources that changes in space and time in response to the shifting nature of the ocean and its users, has been proposed as a solution to balancing marine resource use with the conservation of biodiversity (Hobday et al. 2013, Lewison et al. 2015, Maxwell et al. 2015, Dunn et al. 2016). 
Integrating biological, ecological, environmental, and socioeconomic data collected over multiple spatiotemporal scales to provide information to managers and resource users in near real time, dynamic ocean management is a new paradigm that holds promise for fisheries sustainability (Hobday et al. 2013, Lewison et al. 2015), protected area design (Dunn et al. 2016), and management of populations of highly migratory and protected marine species (Maxwell et al. 2015).

Central to developing dynamic ocean management is the capacity to integrate physical data with information describing the distributions and environmental preferences of marine species, to predict key habitats or productive fishing grounds and track how they shift through time (Hobday et al. 2013). Species distribution models (SDMs; and counterparts known as habitat, habitatbased, species-habitat, habitat suitability, and ecological niche models) are powerful eco-informatics tools that can quantitatively characterize the habitat preferences of mobile marine species such as pelagic fish, cetaceans, seabirds, turtles, and marine mammals (Elith and Leathwick 2009, McGowan et al. 2013, Becker et al. 2014). Through linking data sets describing animal presence or abundance with measures of biophysical conditions, SDM have become a go-to technique for mapping and predicting habitat use by mobile species (Raymond et al. 2015). When combined with data describing the spatial footprint of anthropogenic activities, SDM predictions can also be used to map hotspots of risk for species of conservation concern (Guy et al. 2013, Maxwell et al. 2013, Fossette et al. 2014, Queiroz et al. 2016).

Species presence records for marine SDMs can be obtained from shipboard sightings, systematic surveys, electronic tagging, fisheries observer records and underwater acoustic monitoring technologies. Environmental data are also available from a wide range of sources operating over different spatiotemporal scales, complicating the choices inherent in model construction. For fine-scale, mechanistic analyses of animal-environment interactions, in situ measurements are often the most appropriate (Benoit-Bird et al. 2013, Scott et al. 2013). Earth Observation remote sensing provides physical data over ocean-basin or global scales, matching the wide range of movement of highly migratory species. Improvements in satellite remote sensing have led to the expanded use of remotely sensed environmental data in broad-scale, predictive SDMs in recent years (Hobday et al. 2011, Hobday and Hartog 2014), particularly when combined with animal movement data from satellite telemetry and biologging (Raymond et al. 2015, Hazen et al. 2016).

In addition to satellite remote sensing, ocean circulation models are an emerging source of physical data on which to construct marine SDMs. Use of ocean circulation models, particularly those that incorporate realtime data assimilation, overcomes several of the inherent limitations of remotely sensed data (e.g., cloud cover, surface measurements only, varying spatial and temporal coverage and resolution). Rapid developments in ocean modelling are leading to more frequent use of modelled products for marine eco-informatics, with SDMs based on Regional Ocean Modelling Systems (ROMS) showing comparable performance to those based on in situ data in some applications (Becker et al. 2016). However, the trade-offs in the choice of environmental data for marine SDMs has yet to be adequately explored, particularly regarding the utility of SDMs in generating near real-time predictions for dynamic ocean management and fisheries applications.

Here, we explore these trade-offs, using the California drift gillnet (DGN) fishery as a case study. We model the dynamic distributions and catchability of broadbill swordfish Xiphias gladius, a large, highly migratory, and economically valuable predatory fish that is the main target of the DGN, using only open-source software and freely available environmental data. We seek to make recommendations for the choice of environmental data for modelling the dynamic distributions of highly mobile species in near real time, through comparing SDMs built using physical fields from satellite remote sensing to those based on a data-assimilative California Current configuration of ROMS (Shchepetkin and McWilliams 2005, Neveu et al. 2016). Specifically, we aim to (1) elucidate the physical drivers underlying variation in catchability of broadbill swordfish in the California Current System (CCS); (2) compare performance of satellite and ROMS-based SDMs for near real-time prediction of swordfish catchability; (3) explore the role of SDMs in the development of eco-informatics approaches to dynamic ocean management.

\section{Methods}

All data processing and analytical work was carried out in the R environment (R 3.1.2; R Core Team 2013).

\section{Fisheries observer data}

We used 25 yr (1990-2014) of NOAA fisheries' observer data from the California DGN fishery, which records total catch of swordfish per gillnet set along with set haul location and time. During this period, observer rates were approximately $15 \%$ (Martin et al. 2015). This data set comprised records for 8,665 gillnet sets, 3,235 (37\%) of which had zero swordfish catch. The distribution of fishing effort was variable over the CCS domain through this time period, with most effort concentrated off the coast of Central and Southern California (Fig. 1).

\section{Environmental data}

Earth observation remote sensing.-We selected a suite of physical variables on the basis of their availability, resolution, coverage, and functional relevance to swordfish catch rates (Table 1). We extracted time-matched measures of physical conditions contemporaneous to each set location from the full set of remotely sensed variables. 


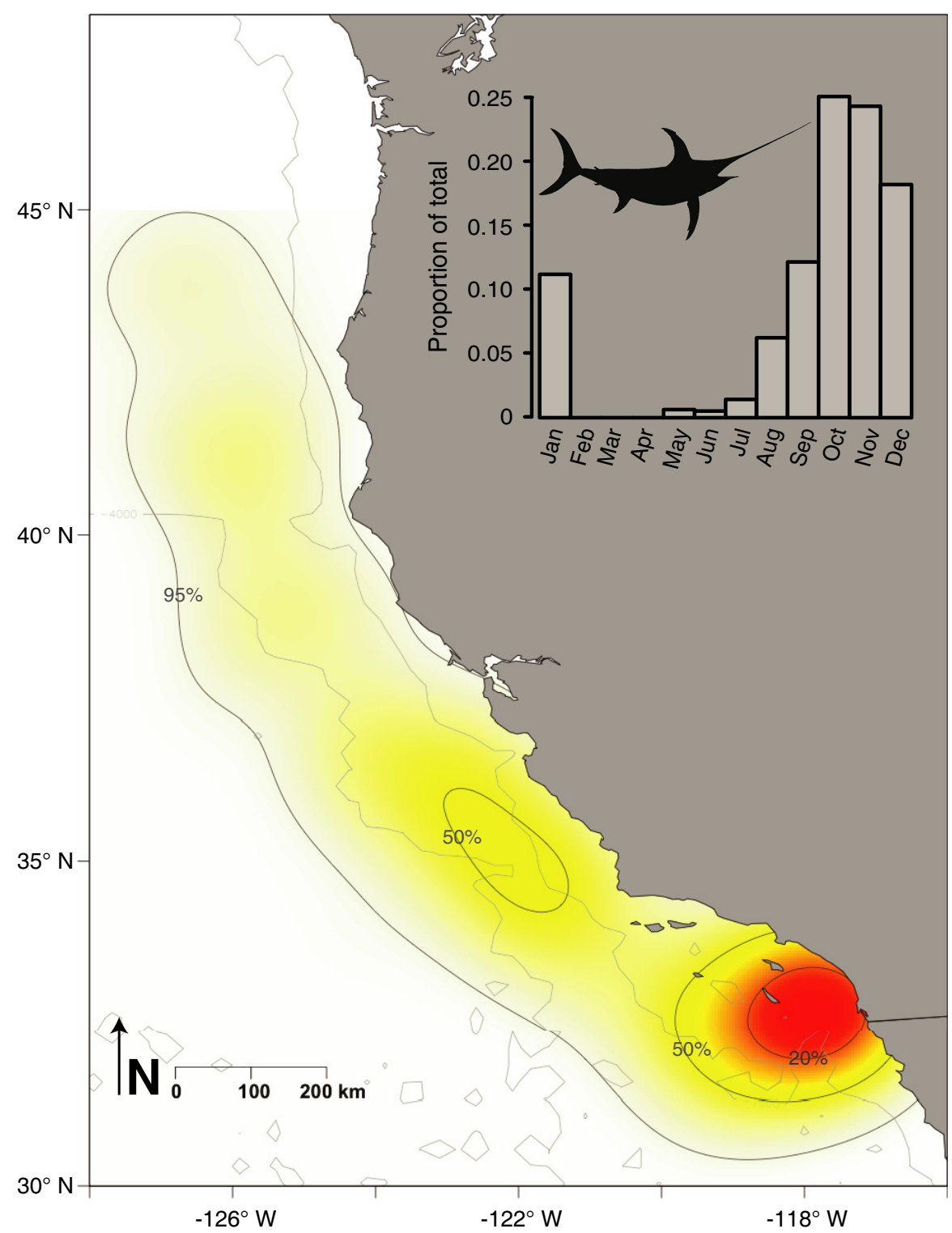

FIG. 1. Fisheries effort. California, USA drift gillnet (DGN) fishery, 1990-2014 (anonymized and spatially smoothed). Spatial distribution of effort is shown as $95 \%, 50 \%$, and 20\% volume contours of Kernel Utilization Distribution (KUD) of all set locations for which fisheries observer data were recorded. Yellow to red shading shows intensification of effort in coastal waters of centralsouthern California, particularly in the Southern California Bight. Temporal distribution of effort over the annual cycle is shown in the inset histogram, as the proportion of the total number of sets in each month over the complete data set. Effort was concentrated in September-January, particularly in late October to early November.

Where product availability did not extend over the entire timespan of fisheries data, we blended products to obtain as complete a temporal coverage as possible. Chlorophyll $a$ data from the SeaWIFS and MODIS sensors were used for different time periods of operation (SeaWIFS 19972002; MODIS 2002-2014). Kahru et al. (2012) compared these data sets extensively for the CCS region, establishing a near $1: 1$ correlation for these data sets $\left(R^{2}=0.961\right)$, so we did not process chlorophyll $a$ data further. We calculated the standard deviation of SST and SSH, both proxies for (sub-)mesoscale frontal activity, over a $3 \times 3$ pixel window, centered on the pixel containing set location. Eddy kinetic energy (EKE; also termed Turbulent Kinetic Energy, TKE) was calculated from AVISO zonal (u) and meridional (v) geostrophic velocity fields:

$$
\mathrm{EKE}=\frac{u^{2}+v^{2}}{2}
$$

For the purposes of prediction, all remotely sensed physical data fields were standardized to the lowest common spatial resolution $\left(0.25^{\circ}\right.$; AVISO altimetry) by 


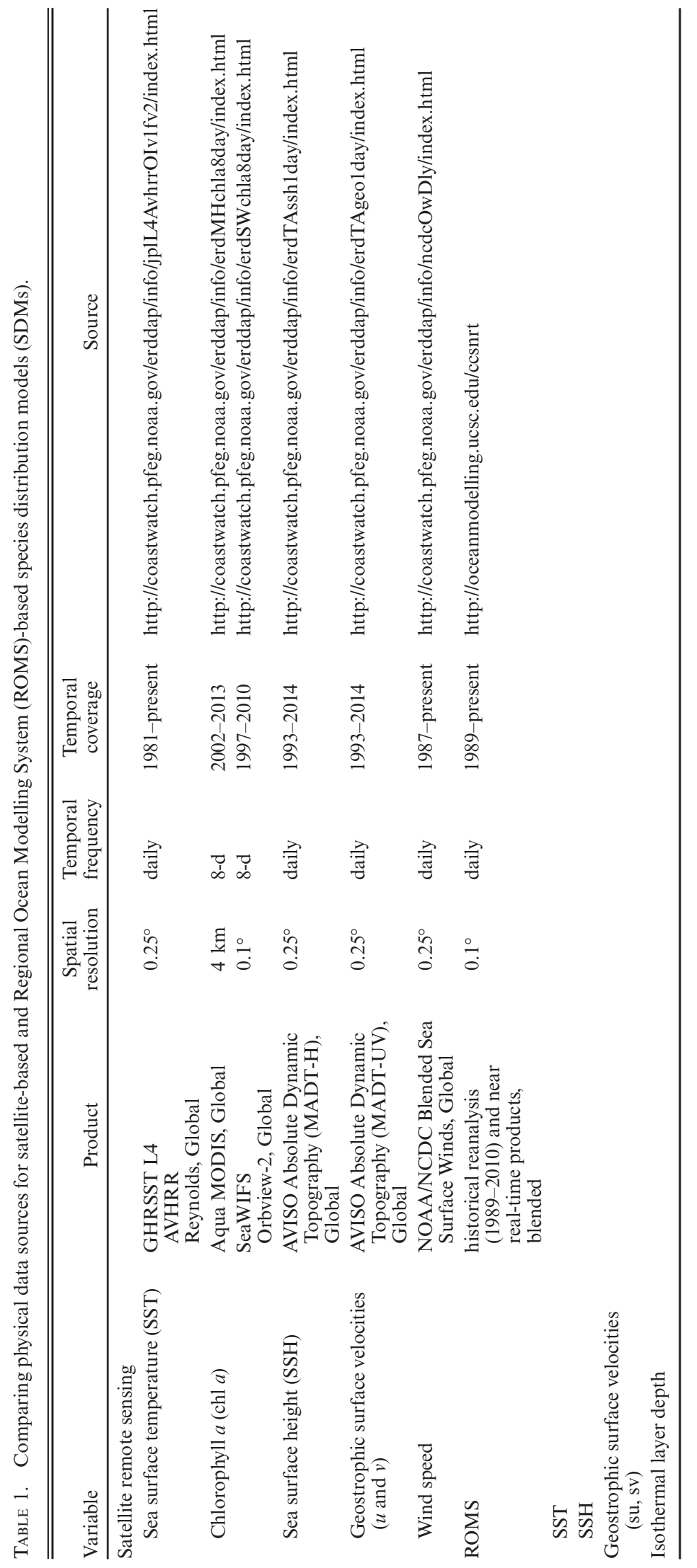


bilinear interpolation prior to extraction of point data (raster package for R; Hijmans and van Etten 2012).

Regional Ocean Modelling System (ROMS).-We extracted a comparable set of physical data for each set location from the CCS configuration of ROMS (Table 1). The CCS ROMS covers the domain $30^{\circ}$ to $48^{\circ} \mathrm{N}$, from the coast to $134^{\circ} \mathrm{W}$, with a $0.1^{\circ}(\sim 10 \mathrm{~km})$ horizontal resolution and 42 vertical layers. Near real-time assimilation of measured data from satellite sensors (SST, SSH) and in situ sources (e.g., temperature and salinity from ship surveys, gliders, buoys) constrains the model, adjusting for minor spatial inaccuracies in the positioning of mesoscale features and optimizing the realism of model-derived physical fields (Broquet et al. 2009). To obtain complete temporal coverage, we blended daily outputs of the 31-yr (1980-2010) historical reanalysis product (Neveu et al. 2016) and a new near real-time (NRT) product (2010-present), available from the University of California Santa Cruz Ocean Modelling and Data Assimilation group (available data online). ${ }^{9}$

The NRT CCS ROMS is configured differently from the historical reanalysis (changes to boundary conditions, data fields assimilated, and method of assimilation), but its output represents a CCS state estimate that is similar to that produced in the reanalysis. Quantitative comparisons confirmed continuity between these model configurations for most variables. A correction factor was applied to the near real-time sea surface height $(\mathrm{SSH})$ fields $(+0.035 \mathrm{~m})$ to ensure continuity between the historical reanalysis and NRT data sets used in SDMs. We also applied some temporal smoothing to the ROMS SSH time series to eliminate process noise, using a Savitzky-Golay filter with a 7-d moving window (signal package for R). Eddy Kinetic Energy was calculated from $u$ and $v$ geostrophic velocity fields. Isothermal Layer Depth (ILD) was defined as the depth at which the temperature was $0.5^{\circ} \mathrm{C}$ cooler than that at the surface. Sea surface salinity, zonal $(u)$ and meridional $(v)$ wind components and wind stress curl fields were not used owing to an observed lack of continuity in these variables between the two model configurations.

In order to develop the best possible model with each set of physical data, we added satellite chlorophyll $a$ as a predictor in ROMS-based models, resampled to match the $0.1^{\circ}$ resolution common to other physical fields from ROMS.

Static physiographic. - Bathymetric data were obtained at one arc-minute resolution from ETOPO1 (Amante and Eakins 2009; data available online). ${ }^{10}$ We extracted mean water depth, and its standard deviation over a $3 \times 3$ pixel moving window, for each set location. The standard deviation of water depth identifies areas of rugosity associated with topographic features of the

\footnotetext{
${ }^{9} \mathrm{http}: / /$ oceanmodelling.ucsc.edu

${ }^{10}$ https://www.ngdc.noaa.gov/mgg/global/global.html
}

seafloor, such as seamounts, ridges, and the continental shelf break.

Lunar phase.-Swordfish are known to respond to changing light conditions through the lunar cycle, moving deeper in the water column during full moon periods (Dewar et al. 2011). We therefore included a quantitative measure of lunar phase, the proportion of lunar illumination, as a predictor of swordfish catchability (lunar library for R; Lazaridis 2014).

\section{Model specification}

In the interests of robustness and to inform technical comparisons, we took a multi-model approach, building both presence-absence (catch vs. zero catch per set, binary response) and catchability (total number of swordfish caught per set, count response) models with each set of environmental data (satellite, ROMS).

Species distribution models: Boosted Regression Trees.Boosted Regression Trees (BRTs) are a flexible class of classification algorithm that operate using machine learning principles (De'Ath 2007, Elith et al. 2008). As such, they are not subject to the caveats of more commonly used techniques such as generalized linear or generalized additive mixed models (GLMM/GAMM). BRTs are tolerant to missing values, outliers, collinearity, and non-independence, and the inclusion of irrelevant predictors (Leathwick et al. 2006). While GLMM/GAMM seek to fit the most parsimonious model to a data set, BRTs combine predictions of many simple models (each classification tree) to maximize robustness and predictive performance. Accordingly, we built BRTs with all available predictors for each set of models.

In fitting BRTs, we adapted the protocols outlined in (Leathwick et al. 2006, Elith et al. 2008, Soykan et al. 2014) and the brt.functions package provided by Elith et al. (2008). Presence-absence models were built with a binomial (Bernoulli) distribution, whereas total catch models used a Poisson distribution. Other options for a count response, such as the Tweedie distribution, have not yet been implemented. However, BRTs are known to be more robust to mis-specification than GAMMs (Leathwick et al. 2006), and the best performing Tweedie power parameters for this data set were in the range $1.2-1.3$, where 1 approximates a Poisson distribution. We used a tree complexity of 3 , a bag fraction of 0.7 , and conducted sensitivity analyses on learning rate ("shrinkage") for each model set, aiming for at least 1,000 trees in final model configurations. Each of these configuration settings is described in detail in Elith et al. (2008). A random number was included as a predictor for each set location in each model run, to compare against the contributions of other variables.

Models were validated and compared using a set of diagnostic metrics and visualization of dynamic 
predictions. For presence-absence models, we used the area under the receiver operating curve (AUC) statistic to assess predictive performance through evaluating the ratio of true positives (correctly classified presences) to false positives. A model predicting the observed presences and absences perfectly would score 1 , whereas one performing no better than chance would score 0.5 . We used leave-one-out cross-validation over the $25 \mathrm{yr}$ of data, leaving each year in turn out of the model fitting ("training") data set and predicting from the model over the data set from that missing year ("testing"), with AUC as the validation statistic. In addition, we compared the total proportion of deviance explained by each of the model sets. For total catch models, we used proportion of deviance explained, and leave-one-out crossvalidation by year with root mean squared error (comparing predicted to observed catch rates) as diagnostics.

\section{Making dynamic near real-time predictions}

We generated a series of daily predictions of the probability of occurrence and catchability of swordfish over the CCS domain by predicting from each SDM over a series of time-matched environmental data fields. For satellite-based models, the spatial resolution of predictive surfaces was set at the lowest common resolution of physical data fields $\left(0.25^{\circ}\right)$. For ROMS-based models, we generated daily predictions at the $0.1^{\circ}(\sim 10 \mathrm{~km})$ resolution common to all fields.

Uncertainty in our models of swordfish catchability was estimated using standard errors in spatial predictions. For per-grid cell standard errors in daily predictions, we fitted BRTs using the whole data set 10 times, with a slow learning rate and bag fraction of 0.6 to include stochasticity in each model run. We then made spatial predictions of swordfish catchability over the study domain from each of these model objects and estimated lower and upper confidence bounds using the standard error of each set of predictions. To estimate spatial variability and uncertainty in daily predictions, we generated monthly summaries of probability of presence and catchability (total catch) through calculating the mean and standard deviation of predicted values per grid cell over 30 days of daily predictive surfaces (1-30 November 2014).

\section{RESULTS}

\section{Model performance}

Dynamic SDMs based on physical data fields from satellite remote sensing and ROMS performed comparably well in this context, confirming that data-assimilative regional ocean models can produce near real-time predictions of the distributions of migratory marine species with comparable accuracy to models built using satellite remote sensing (Table 2). Satellite-based SDMs demonstrated marginally better performance under the
TABLE 2. Model performance diagnostics.

\begin{tabular}{lcc}
\hline \hline Response variable & Satellite & $\begin{array}{c}\text { Regional Ocean } \\
\text { Modelling System }\end{array}$ \\
\hline Presence & & \\
$\quad$ AUC & 0.856 & 0.813 \\
$\quad$ KFCV mean AUC & 0.782 & 0.763 \\
$\quad$ Deviance explained (\%) & 12.2 & 12.2 \\
Total catch & & 6.6 \\
$\quad$ RMSE (\% maximum) & 6.3 & 8.9 \\
$\quad$ KFCV mean RMSE & 9.3 & 21.4 \\
(\% maximum) & & \\
$\quad$ Deviance explained (\%) & 24.5 & \\
\hline
\end{tabular}

Note: AUC, area under the receiver operating curve; RMSE, root mean squared error; $\mathrm{KFCV}, \mathrm{K}$-fold cross-validation.

diagnostic measures we applied, including through leaveone-out cross-validation by year, yet the slight differences in model performance that we observed did not manifest in an appreciable increase in spatial uncertainty in near real-time predictions. Indeed, the direct comparability in model performance combined with the tradeoffs involved in the selection of physical data on which to construct marine SDMs (Table 3) lead us to recommend the use of regional ocean models for dynamic ocean management, where available.

Our findings suggest that modelling count responses, such as the total catch per set metric used here, can result in better performing models of the catchability of highly migratory marine species than simpler presenceabsence models (Table 2).

\section{Physical drivers of swordfish catchability}

We demonstrate clear linkages between the dynamic physical environment and the catchability of broadbill swordfish in the CCS. Across all models, each of the physical predictor variables contributed more to the total explanation of deviance than would be expected by chance (random number had lowest relative variable contribution).

In predicting the relative probability of swordfish presence over the CCS domain, ROMS-based models identified isothermal layer depth (ILD) as the most influential predictor, with elevated probabilities of swordfish catch in the 20-80 m ILD range (Figs. 2, 3). Water depth was identified as an important predictor, with an evident preference for deeper waters offshore of the continental shelf $(>1,500 \mathrm{~m})$ and in small-scale basins of the Southern California Bight; Figs. 2, 3). Sea surface temperature (SST) strongly influenced the probability of swordfish presence, with both satellite and ROMS-based models identifying a comparable peak in likelihood in the 15$20^{\circ} \mathrm{C}$ range (Fig. 2).

Catchability (total catch per set) responses to physical predictors were broadly comparable to those of presenceabsence models, except for the higher relative importance of zonal wind speed from satellites, and SSH from both 
TABLE 3. Respective advantages and disadvantages of remotely sensed satellite data and physical data from ROMS for building dynamic species distribution models with the capability for making near real-time predictions.

\begin{tabular}{|c|c|c|}
\hline Factor & Satellite & ROMS \\
\hline $\begin{array}{l}\text { Common spatial resolution among physical } \\
\text { data fields }\end{array}$ & no (standardized at $0.25^{\circ}$ ) & yes $\left(0.1^{\circ}\right)$ \\
\hline $\begin{array}{l}\text { Common temporal frequency among physical } \\
\text { data fields }\end{array}$ & no (range daily-weekly) & yes (daily) \\
\hline Cloud-affected & yes & no \\
\hline Global coverage & yes & $\begin{array}{l}\text { no }\left(\text { CCS domain: } 30^{\circ}-48^{\circ} \mathrm{N}\right. \\
\left.115^{\circ}-134^{\circ} \mathrm{W}\right)\end{array}$ \\
\hline Continual data coverage & yes, dependent on sensor functionality & $\begin{array}{l}\text { no, dependent on data processing and } \\
\text { storage }\end{array}$ \\
\hline Near real-time provision & $\begin{array}{l}\text { yes, timing dependent on composite } \\
\text { product availability }\end{array}$ & yes, continual data assimilation \\
\hline Availability of ocean color, biogeochemistry & yes & no \\
\hline Availability of sub-surface physical data & no & yes \\
\hline Satellite sensor failure leads to data loss & yes & no \\
\hline
\end{tabular}

Note: ROMS, Regional Ocean Modelling Systems; CCS, California Current System.

satellite and ROMS (Figs. 2-4). Isothermal layer depth (ILD) made an important explanatory contribution to predicted catchability of swordfish, with comparable responses in both presence-absence and total catch models except for a clearer peak in the $30-40 \mathrm{~m}$ depth range in predicting total catch (Figs. 2, 4). Isothermal layer depth was found to be a more useful predictor of swordfish presence than zonal wind speed from satellites $(\mathrm{ILD}=23.2 \%$; zonal wind $=8.7 \%)$, although this difference was less pronounced in modelling a total catch response $(\mathrm{ILD}=11.8 \%$; zonal wind $=14.2 \%$; Figs. $2-4$ ). ILD and zonal wind are intrinsically related, and could be used as proxies for the same proximate physical processes (e.g., surface mixing resulting from wind stress). However, the importance of ILD in the predictive capabilities of our models exemplifies the clear advantages of using three-dimensional data fields available from ROMS over surface-only, two-dimensional, remotely sensed fields in predicting distributions of mobile species. Future work could consider inclusion of other ROMS-derived physical data such as more accurate wind fields and measures of conditions at depth, such as vertical velocity, a proxy for upwelling strength.

Measures of mesoscale variability including $\mathrm{SSH}$, zonal wind speed, EKE, chlorophyll $a$ concentration, and the local standard deviation in SST, SSH, and water depth all had a moderate influence in predicting the relative catchability of swordfish (Figs. 2-4), and contributed to the spatiotemporal dynamics evident in daily predictions (see animations in Data S1; Figs. 3, 5, 6). Swordfish catchability was found to be highest in association with positive SSH anomalies, although we did observe some differences in the shape of responses to SSH from AVISO satellites to SSH from ROMS.

Low to intermediate chlorophyll $a$ values were the most likely to be associated with swordfish presence, although chlorophyll $a$ had a limited influence in both presence-absence and total catch models ( $8-9 \%$ relative contribution to total explanatory power; Figs. 2-4). Zonal wind velocities from satellites influenced swordfish catch probabilities, with moderate northerly winds $(\sim 10 \mathrm{~m} / \mathrm{s})$ most influential in predicting swordfish presence $(9 \%$ variable contribution; Fig. 2) and total catch (15\% variable contribution; Fig. 4). Lunar phase influenced catch probabilities $(6-7 \%$ relative variable contribution), with concurrence in the shape of responses among all models. Swordfish catchability was found to be highest during the relative darkness of a new moon $(<20 \%$ lunar illumination; Figs. 2, 4) than in the days approaching the full moon, the illumination from which drives prey deeper into the water column. Standard deviation in water depth, a proxy for seafloor rugosity, had a greater contribution to catchability models (8-9\%; Fig. 4) than to relative probability of presence predictions (4-5\%; Fig. 2).

Dynamic daily predictions (Fig. 3) of relative swordfish catchability in the CCS domain over the $30 \mathrm{~d}$ of November 2014 are presented as animations in Data S1. Spatiotemporal dynamics in predicted swordfish catchability are summarized as monthly mean and standard deviation per grid cell, showing higher uncertainty in predictions of swordfish catchability in regions of intense mesoscale variability (Figs. 5, 6). The influence of mesoscale circulation is most evident in ROMS-based predictions (Figs. 3, 5, 6; Data S1), yet also somewhat apparent in lower-resolution satellite-based models, which included measures of SSH, EKE, and chlorophyll $a$ concentration (Figs. 3, 5, 6).

\section{DisCUSSION}

Using marine eco-informatics for dynamic ocean management requires a well-informed understanding of the relative advantages of modelling approaches, and the predictive capacities of resulting models. SDMs are becoming a standard tool in marine conservation, yet there is no off-the-shelf technique for spatially dynamic management applications. Trade-offs associated with model construction and the choice of physical data are 

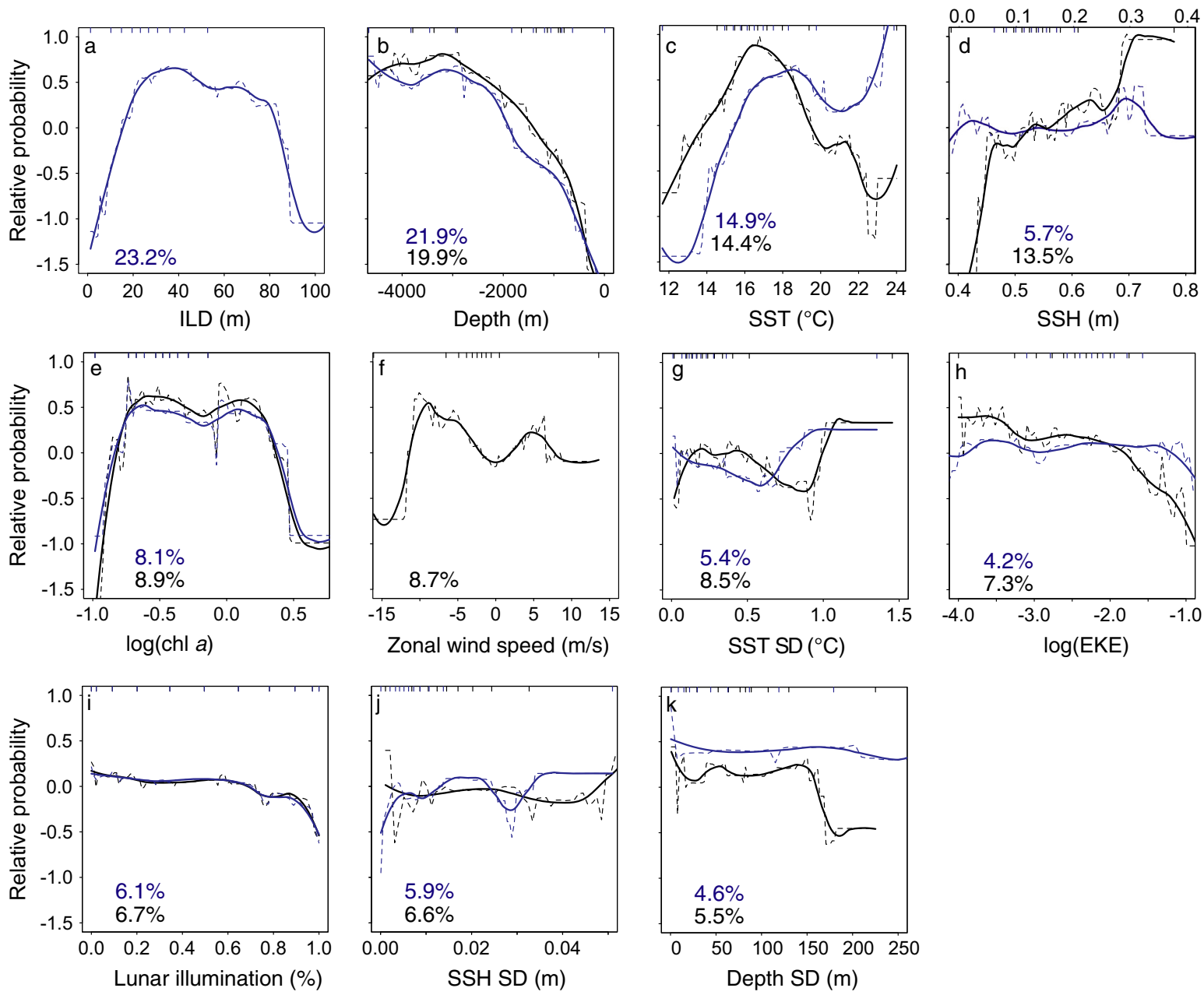

FIG. 2. Predicting swordfish presence. Partial dependence plots of presence-absence boosted regression trees (BRTs), showing relative probability of the presence of swordfish as a response to (a) isothermal layer depth (ILD), (b) water depth, (c) sea surface temperature (SST), (d) sea surface height (SSH), (e) chlorophyll $a$ concentration (measured $\mathrm{as} \mathrm{mg} / \mathrm{m}^{3}$ ), (f) zonal wind speed, (g) standard deviation of SST, (h) eddy kinetic energy (EKE; measured as $\mathrm{cm}^{2} \mathrm{~s}^{-2}$ ), (i) lunar illumination (percentage of surface illuminated), (j) standard deviation of SSH, (k) standard deviation of water depth. Responses of species distribution models (SDM) constructed using remotely sensed environmental data suite, at $0.25^{\circ}$ resolution, in black. Responses of SDM constructed using Regional Ocean Modelling System (ROMS) data suite, at $0.1^{\circ}$ resolution, in blue. Variables not common to both data sets (isothermal layer depth, panel a, and zonal wind speed, panel f) are plotted individually.

often overlooked, affecting the validity of predictions. Our methodological exploration establishes, for the first time, that species distribution models for highly migratory species built upon physical data from data-assimilative regional ocean models can perform as well as those built upon remotely sensed data sets, and have distinct advantages for operationalizing near real-time ecoinformatics in support of dynamic ocean management.

\section{Swordfish catchability in the California Current System}

Our findings establish that swordfish are more likely to be caught by the California Drift Gillnet (DGN) fishery, and in greater numbers, in waters in the $14-20^{\circ} \mathrm{C}$ surface temperature range in the CCS. In all models, we found relative probability of occurrence of swordfish to be highest in deep offshore waters with low to intermediate chlorophyll $a$ concentrations, and a relatively deep isothermal layer. Predictions of highest probability of occurrence are in the offshore deep pelagic realm, as might be expected for this ocean-wandering species.

Broadbill swordfish are cosmopolitan, with a circumglobal distribution and broad latitudinal range $\left(50^{\circ} \mathrm{N}-\right.$ $50^{\circ} \mathrm{S}$; Nakamura 1985). Owing to physiological adaptations that regulate blood temperature, swordfish can tolerate a broad range of thermal conditions $\left(\sim 2^{\circ} \mathrm{C}\right.$ to $\sim 32^{\circ} \mathrm{C}$; Costa and Sinervo 2004, Evans et al. 2014), although they are most frequently associated with surface waters in the $16-24^{\circ} \mathrm{C}$ range. Hence, anywhere in the global ocean save the extreme polar regions could be classed as suitable swordfish habitat. Yet, the dynamic distributions of this commercially valuable species at 

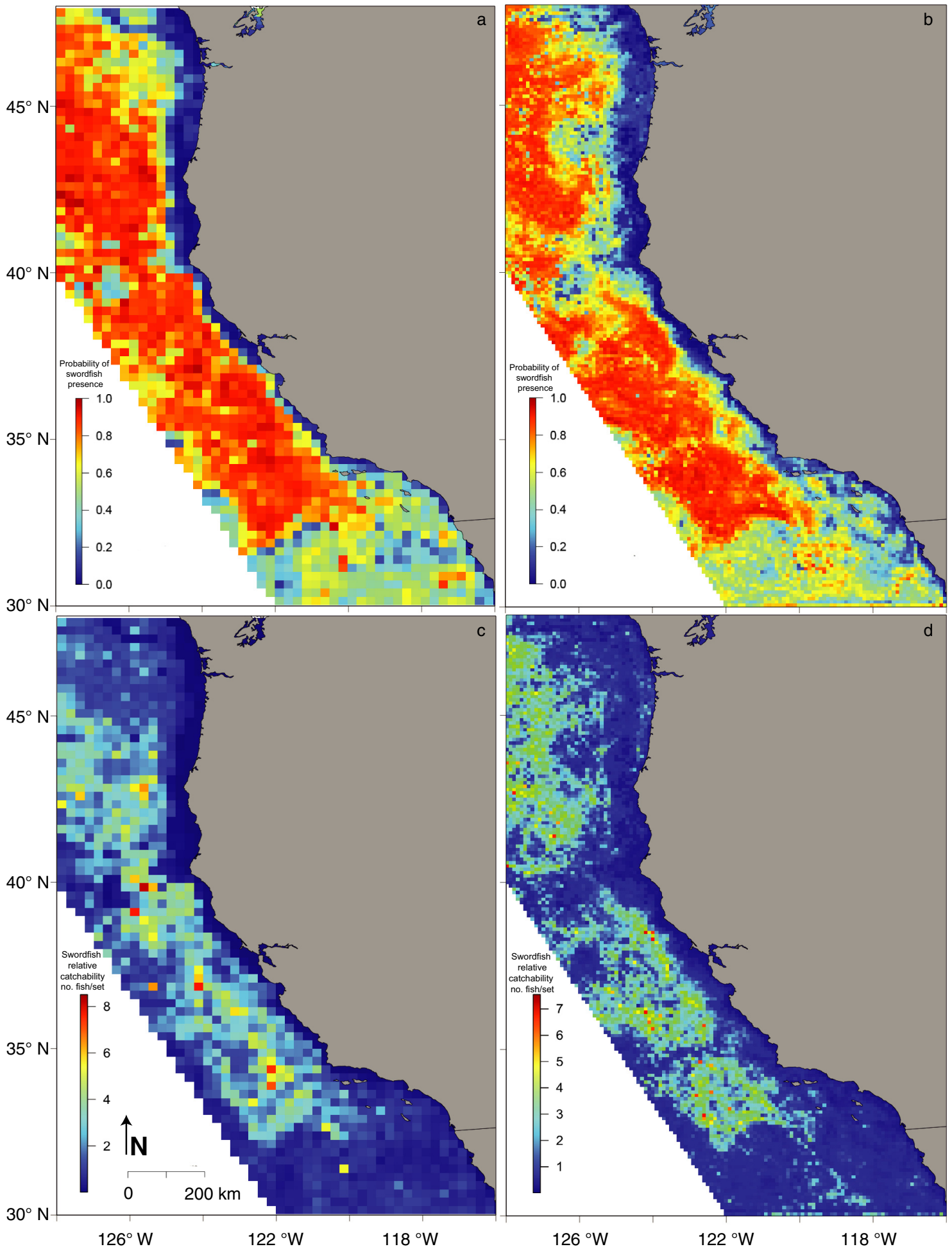

FIG. 3. Near real-time daily predictions of swordfish catchability. (a, b) Relative probability of presence of swordfish over the California Current System (CCS) domain for 1 November 2014, predicted using (a) presence-absence SDM constructed using remotely sensed physical data and (b) presence-absence SDM constructed using physical data from Regional Ocean Modelling System (ROMS). (c, d) Relative catchability (total predicted catch) of swordfish over the CCS domain for 1 November 2014, from (c) SDM constructed using physical data from satellite remote sensing, with count response; (d) SDM constructed using physical data from Regional Ocean Modelling System (ROMS), with count response. 

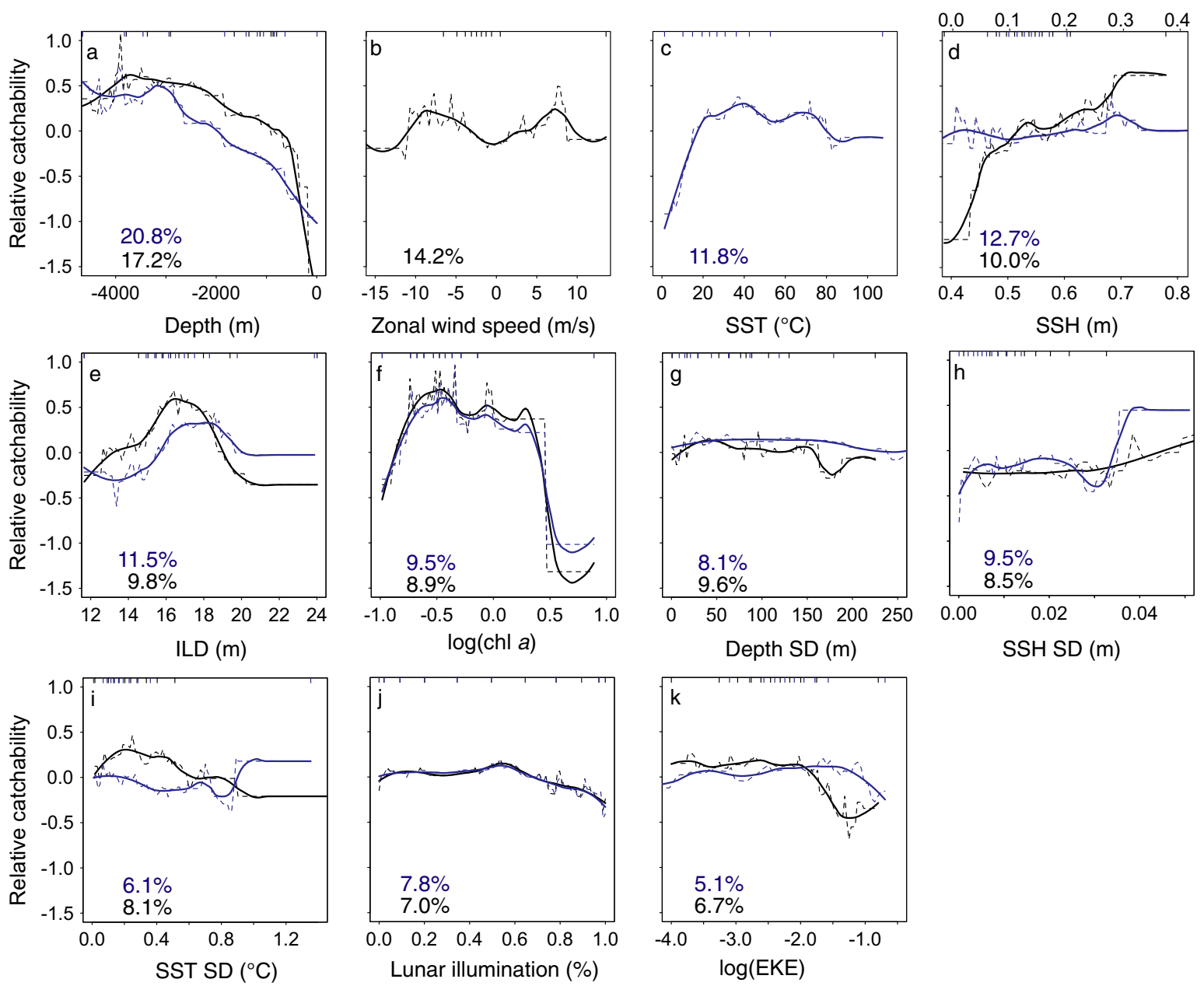

FIG. 4. Predicting swordfish catchability. Partial dependence plots of boosted regression trees (BRTs) with count response, showing relative catchability of swordfish as a response to (a) water depth, (b) zonal wind speed, (c) isothermal layer depth, (d) sea surface height, SSH, (e) sea surface temperature, SST, (f) chlorophyll a concentration (measured as $\mathrm{mg} / \mathrm{m}^{3}$ ), (g) standard deviation of water depth, (h) standard deviation of SSH, (i) standard deviation of SST, (j) lunar illumination (percentage of surface illuminated), (k) eddy kinetic energy, EKE. Responses of SDM constructed using remotely sensed physical data, at $0.25^{\circ}$ resolution, in black. Responses of SDM constructed using Regional Ocean Modelling System (ROMS) data, at $0.1^{\circ}$ resolution, in blue. Variables not common to both data sets (zonal wind speed, panel b, and isothermal layer depth, panel c) are plotted individually.

regional scales are known to be structured by responses to the physical environment (Bigelow et al. 1999, Morato et al. 2010, Sepulveda et al. 2010).

Water depth was the most important predictor of both swordfish presence and catch rates across our models. In common with our findings, a study in the North Atlantic using longline data found that bathymetric variables were the best predictors of swordfish catch (Hsu et al. 2015). Seafloor rugosity was an important predictor of catch rates in total catch models, consistent with complex seafloor topographies and bathymetric features acting as drivers of swordfish aggregation. Seamounts, underwater mountain systems that are aggregation sites for a diverse range of predatory marine vertebrates (Morato et al. 2010), are known to be areas of increased catchability of swordfish (Young et al. 2011, Bouchet et al. 2015, Hsu et al. 2015). Alongside a preference for deeper offshore areas, the waters overlying complex seafloor topographies in the Southern California Bight and bathymetric features such as Davidson Seamount are higher-than-average regions of swordfish catchability in the CCS.

Given that the CCS is known to be an important foraging ground for swordfish, distributions are likely tied to the availability of food resources. Swordfish are known to feed opportunistically upon a range of midtrophic-level pelagic species associated with the deep scattering layer, with ommastrephid cephalopods such as the jumbo squid Dosidicus gigas as preferred prey items (Markaida and Hochberg 2005, Young et al. 2006, Hsu et al. 2015). These prey are diel migrators, typically moving into surface waters at night and back to depths 

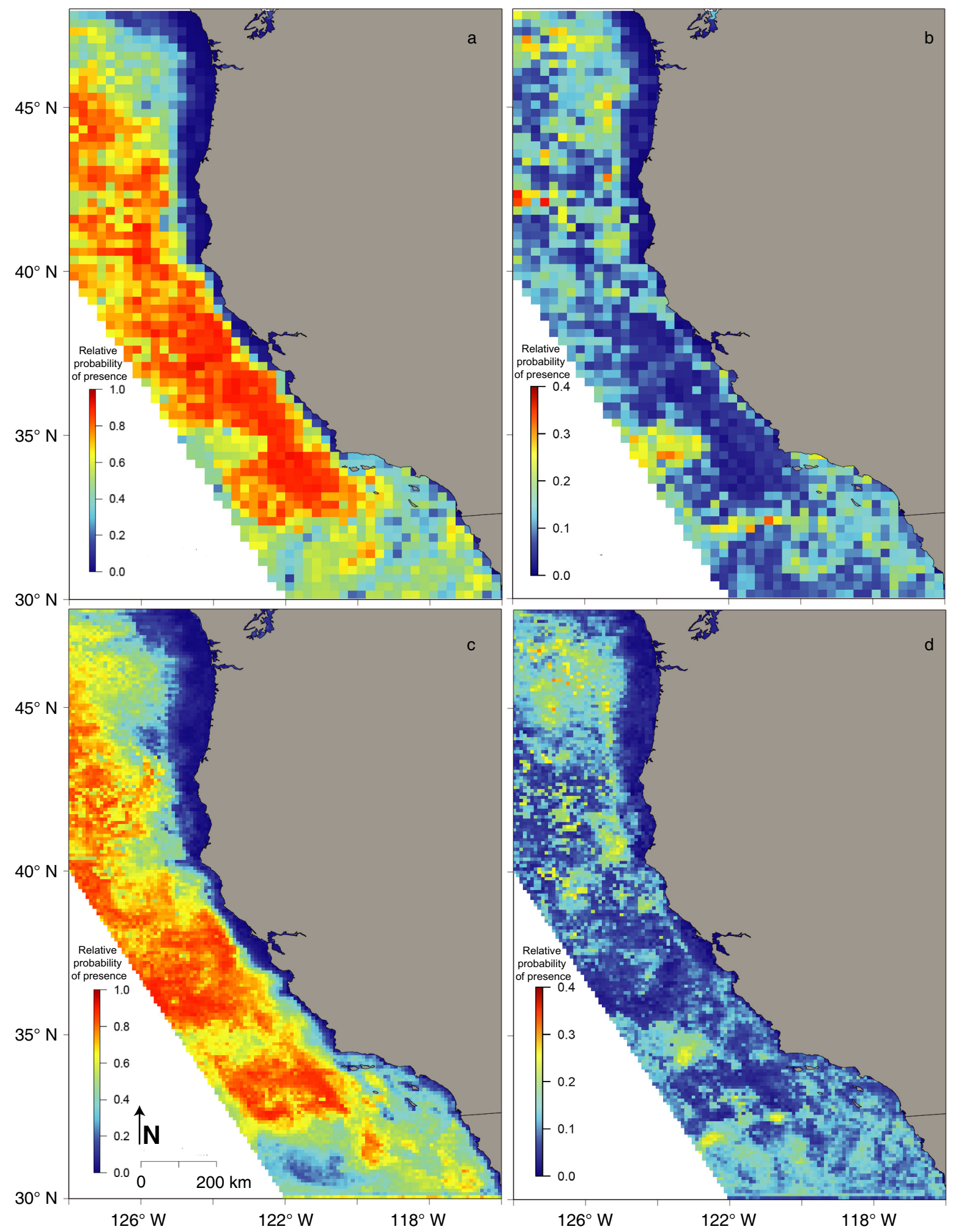

FIG. 5. Summarized monthly predictions of swordfish catchability (relative probability of presence). (a) Mean and (b) standard deviation of relative probability of swordfish presence per grid cell, from presence-absence SDM constructed using remotely sensed physical data. (c) Mean and (d) standard deviation of relative probability of swordfish presence per grid cell, from presence-absence SDM constructed using physical data from Regional Ocean Modelling System (ROMS). 


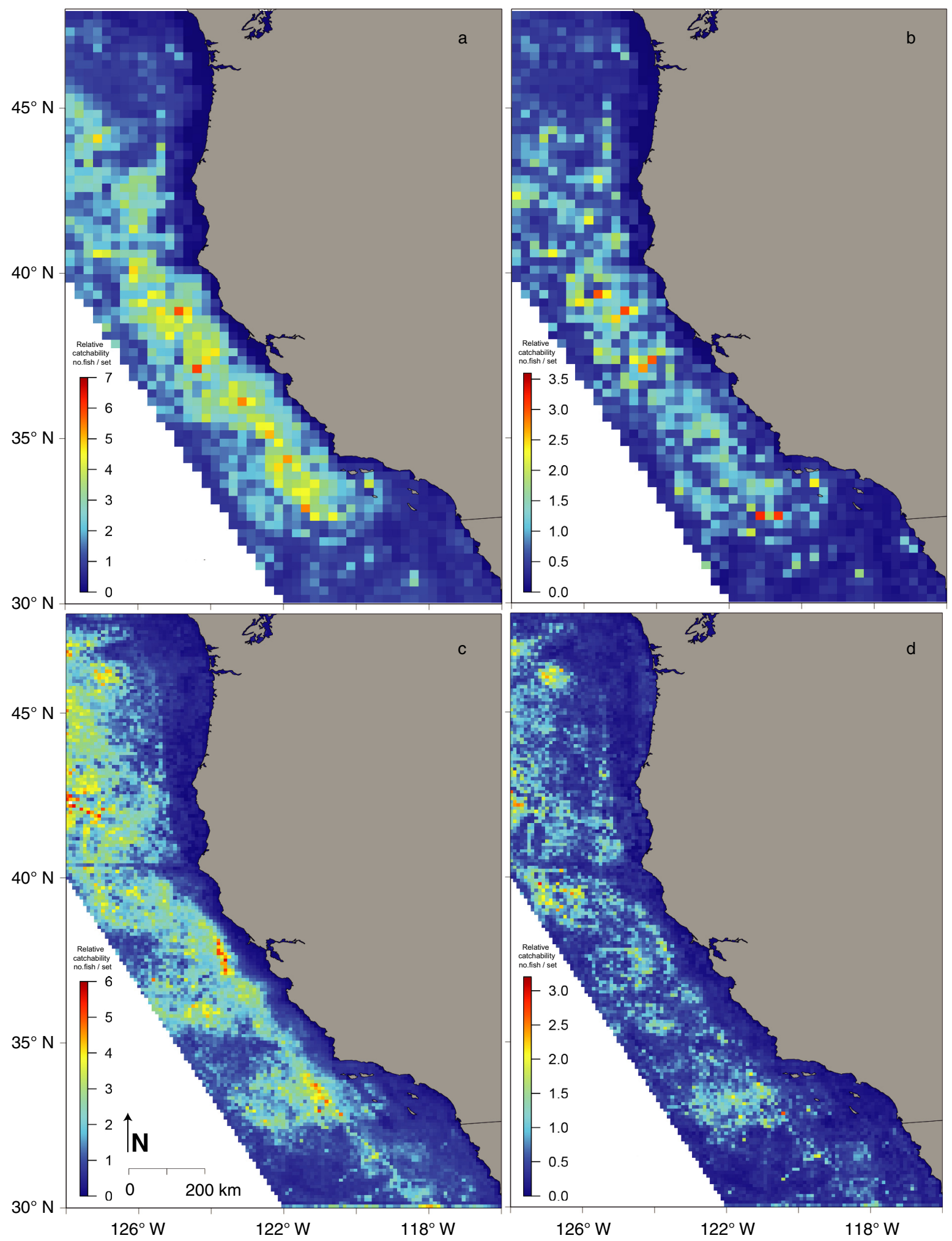

FIG. 6. Summarized monthly predictions of swordfish catchability (total catch). (a) Mean and (b) standard deviation of predicted total swordfish catch per grid cell, from count-response SDM constructed using remotely sensed physical data. (c) Mean and (d) standard deviation of predicted total swordfish catch per grid cell, from count-response SDM constructed using physical data from Regional Ocean Modelling System (ROMS). 
below the mixed layer during the day, followed by their predators. It is at night that swordfish are targeted in the DGN fishery. Their depths, both day and night, are linked to light levels through the water column, and consequently influenced by lunar phase. Around the full moon, swordfish occur deeper in the water column and their depth range expands (Abascal et al. 2010, Dewar et al. 2011, Abecassis et al. 2012). This shift in vertical distribution, and potentially an increased ability to see and avoid fishing gear, reduces catch rates during the full moon. Although swordfish are as likely to be present in suitable habitats during the days surrounding the full moon, they are less likely to be present at the depth range targeted by the DGN. This illustrates the value of including both spatial and temporal, dynamic and static environmental predictors in models of the dynamic distributions of highly mobile marine species.

Previous work on swordfish habitat preferences in this region and elsewhere has revealed associations with mesoscale features such as frontal systems (Podestá et al. 1993, Bigelow et al. 1999, Seki et al. 2002, Young et al. 2011). Despite the lack of availability of environmental data at fine spatial resolutions, the influence of mesoscale variability is evident in model predictions. Swordfish were marginally more likely to be caught in association with positive SSH anomalies, which may reveal a preference for anticylonic eddies or the warm side of a thermal front. Eddy kinetic energy and spatial standard deviation in SST and SSH fields also had a limited positive influence on catch rates. However, in concordance with Hsu et al. (2015), these measures of mesoscale activity did not contribute significantly to the explanation of deviance in our models of catch rates.

The influence of frontal systems on swordfish habitat selection warrants further investigation, with a derived metric of frontal activity likely to improve our capacity to model these associations (Scales et al. 2014, Cotté et al. 2015). Making derived frontal products freely available on the data platforms such as those used here would rapidly facilitate this process. Similarly, measures of oxygen concentration through the water column would likely improve the predictive capacity of SDMs for highly migratory marine species, although broadbill swordfish are known to be more tolerant to low oxygen concentrations than other species (Abascal et al. 2010).

\section{Using ROMS to build marine SDMs}

The choice of environmental data upon which SDMs are based is central to predictive performance. Our findings provide objective validation that ROMS-based SDMs can perform as well as those built on satellite models in a fisheries management context.

This is corroborated by the comparison of ROMSbased SDMs predicting relative densities of cetaceans with models developed using in situ measures of the contemporaneous physical environment presented in Becker et al. (2016).
Data-assimilative regional ocean models integrate data from satellite remote sensing and in situ sampling from buoys, gliders and ship surveys, for realistic forcing of physical data fields. Hence, data-assimilative ROMS such as that used here have the same advantages as satellite remote sensing data for SDMs, yet are not subject to the same limitations (Table 3), including the varying spatial resolution and temporal frequency among satellite-borne sensors; time periods of sensor coverage; gappiness owing to cloud cover; availability of surface variables only; obtaining and integrating data sets from multiple disparate sources; bridging between the same product from different sensors (e.g., chlorophyll $a$ from VIIRS/MODIS/SeaWIFS).

The CCS configuration of ROMS does not yet provide measures of productivity comparable to satellite chlorophyll $a$ products. Chlorophyll $a$ concentration had limited influence in our models, but adding available satellite chlorophyll $a$ to ROMS-based models improved predictive performance over the use of physical fields alone. Although surface productivity is not likely to be a good measure of the distribution of mesopelagic squid and fish that are the preferred prey of broadbill swordfish, the inclusion of biogeochemical variables as proxies of prey distribution is a natural corollary to this work in in improving predictive capabilities of marine SDMs for dynamic ocean management.

Regional ocean models are becoming increasingly sophisticated, incorporating biogeochemistry (Song et al. 2016) and, in some instances, higher trophic level responses to biophysical conditions (Fiechter et al. 2016). Non-assimilative ROMS configurations that incorporate biogeochemistry, such as nutrient cycling, primary and secondary production, and pelagic fish distributions have been developed for this region (Fiechter et al. 2014, Rose et al. 2015, Kaplan et al. 2016) and others (Gutknecht et al. 2013, Rousseaux et al. 2013). However, these nonassimilative models can only be useful in this context where the important variability is not related to mesoscale activity (e.g., eddies, fronts may not be in the right place at the right time). Real-time assimilation of both physical and biogeochemical data will improve the realism of nowcasts and hence the applicability of outputs for ecoinformatics in fisheries management.

In contrast to satellite remote sensing, ROMS generates continuous three-dimensional fields in user-defined time steps. The availability of sub-surface information is critical to the comparative value of regional ocean models for modelling the drivers of distributions of true pelagic species that use a large portion of the water column, such as swordfish. Here, we used daily ROMS outputs to predict relative probability of occurrence, generating dynamic predictions that change daily in response to shifting oceanographic conditions. While some satellite products are available in daily time steps (e.g., Global High Resolution SST, GHRSST), many are served as multi-day composites (e.g., MODIS-Aqua chlorophyll a), which limits their utility for making predictions at 
finer temporal scales. Using ocean models as a source of environmental data confers opportunity for improving temporal resolution: the CCS ROMS configuration generates continuous output, capturing (sub-)mesoscale oceanographic conditions that are contemporaneous to the response data set. Consequently, predictions of probability of fish presence or catchability could be generated from marine SDMs based on ROMS in near real time.

However, while Earth Observation satellites generate freely available, global data sets, regional ocean models have not been implemented everywhere (but see Penven et al. 2001, Koné et al. 2013, da Rocha Fragoso et al. 2016), and are not widely available as a data-assimilative, near-real-time product. As a result, techniques presented here are more applicable to data-rich than data-poor systems, and may not yet be achievable in developing countries, where spatially explicit data are often lacking but fisheries management solutions are most urgently required (Metcalfe et al. 2016). Satellite data would be the logical choice of environmental data where regional ocean models have not yet been developed or are not operationalized for near-real-time provision.

\section{Predicting catchability of pelagic fish: presence-absence or total catch?}

Whether models seek to predict a presence-absence or count response influences predictive performance and the usefulness of predictions for spatial management. Predictions of our presence-absence and catchability models for swordfish in the CCS were broadly comparable, with the offshore region dominating the highest probabilities for both. However, areas of highest predicted swordfish catchability were not always co-located with highest relative probability of occurrence, and catchability models showed better predictive performance than presence-absence responses. The differences in responses to environmental conditions that we observed among models indicates that we can begin to separate the drivers of distribution and aggregation for swordfish in the CCS, but understanding these mechanisms with confidence would require further fisheriesindependent data for model validation.

The environmental drivers of fish densities may be more nuanced than those of distributions (Hazen et al. 2013a), and yet understanding these nuances is critical to fisheries management. Correlative approaches such as those presented here are useful for identifying physical drivers of regional distributions, but cannot capture the complex mechanisms that drive habitat preference for animals that are known to respond to a range of intrinsic (e.g., ontogenetic changes, breeding cycles) and extrinsic (i.e., environmental conditions) motivations. Identifying these mechanisms using correlative SDMs and fisherydependent data is particularly difficult for cosmopolitan species, especially where response data sets cover a limited geographical extent. Moving forward, eco-informatics approaches to fisheries management may need to extend the approaches exemplified here to encompass mechanistic modelling of animal-environment interactions at finer scales, and towards joint species distribution models (Pollock et al. 2014).

We have modelled relative densities of swordfish caught in drift gillnets over the CCS domain with reasonable predictive performance. However, fisheries are primarily concerned with profitability and therefore size of catch, rather than overall distribution. Modelling absolute densities would be highly desirable for the optimization of fisheries management, yet is more complex, data-intensive, and potentially error-ridden. Moreover, we do not have all the information necessary for a complete understanding of the spatial dynamics of the DGN fishery as observer coverage rates are only $\sim 15 \%$ (Martin et al. 2015) and choice of fishing location is dependent on factors other than just fish distribution (Soykan et al. 2014). Modelling absolute densities of target and non-target species remains a major challenge for ecoinformatics solutions to fisheries management.

\section{Eco-informatics for dynamic ocean management}

While marine resource management solutions are urgently required, particularly for fisheries targeting commercially valuable yet highly migratory species such as tuna and billfish, dynamic ocean management is currently in its infancy. Here, we demonstrate the potential for marine eco-informatics to contribute to fisheries management. We establish the utility of data-assimilative regional ocean models for building dynamic species distribution models for pelagic species. ROMS-based SDMs can provide accurate, high-resolution, high frequency, gap-free predictions of the catchability of pelagic fish in near real-time. Techniques presented here could be applied across a wide range of marine resource management contexts, and in modelling the dynamic distributions of other migratory marine vertebrates, including bycatch-sensitive and protected species.

Ecological forecasting, the capacity to predict future ecosystem responses to environmental change, is likely to become critical to decision making in fisheries management as marine systems respond to climate change (Luo et al. 2011). Seasonal forecasts based on broad-scale indices such as temperature are being developed (Kaplan et al. 2016, Siedlecki et al. 2016) and used to inform fisheries management (Hobday et al. 2011). However, extrapolation of species distribution models across space and time can lead to poor predictive performance (Torres et al. 2015, Sequeira et al. 2016). Where ecoinformatics is based on near-real-time data assimilation, including the capacity for refinement and refitting of predictive models as new data are acquired, now-cast predictions will respond directly and continually to changing environmental conditions (Kaplan et al. 2016). The capacity to forecast future distribution shifts as climate change impinges upon the marine environment (Hazen et al. 2013b, Bost et al. 2015) would be a boon for dynamic ocean 
management, particularly where the spatial and temporal scales of prediction can be aligned with those required for management strategy evaluation.

\section{ACKNOWLEDGMENTS}

Funding for this work was supplied through a multi-year NASA 440 Earth Science Division/Applied Sciences Program's ROSES-2012 A.36 Ecological Forecasting Grant (NNH12ZDA001N-ECOF). We gratefully acknowledge the ongoing cooperation of the California drift gillnet fishery, and NOAA fisheries observers. The authors thank Toby Garfield, Elizabeth Becker, and two anonymous referees for constructive comments on earlier drafts. This work was partly conducted under the remit of an IMBER Climate Impacts on Oceanic Top Predators (CLIOTOP) Task Team, "Dynamic ocean management and seasonal forecasting for pelagic ecosystems." We thank the satellite data providers (NOAA, NASA, AVISO), data servers (NOAA CoastWatch Environmental Resource Division Data Access Portal, ERDDAP), and University of California Ocean Modelling group for support with data acquisition and processing.

\section{Literature Cited}

Abascal, F. J., J. Mejuto, M. Quintans, and A. Ramos-Cartelle. 2010. Horizontal and vertical movements of swordfish in the Southeast Pacific. ICES Journal of Marine Science 67: 466-474.

Abecassis, M., H. Dewar, D. Hawn, and J. Polovina. 2012. Modelling swordfish daytime vertical habitat in the North Pacific Ocean from pop-up archival tags. Marine Ecology Progress Series 452:219-236.

Amante, C., and B. W. Eakins. 2009. ETOPO1 1 Arc-Minute Global Relief Model: procedures, data sources and analysis. NOAA Technical Memorandum NESDIS NGDC-24. National Geophysical Data Center, NOAA. https://doi.org/ $10.7289 / \mathrm{v} 5 \mathrm{c} 8276 \mathrm{~m}$.

Becker, E. A., K. A. Forney, P. C. Fiedler, J. Barlow, S. J. Chivers, C. A. Edwards, A. M. Moore, and J. V. Redfern. 2016. Moving towards dynamic ocean management: How well do modelled ocean products predict species distributions? Remote Sensing 8:149.

Becker, E. A., K. A. Forney, D. G. Foley, R. C. Smith, T. J. Moore, and J. Barlow. 2014. Predicting seasonal density patterns of California cetaceans based on habitat models. Endangered Species Research 23:1-22.

Benoit-Bird, K. J., B. C. Battaile, S. A. Heppell, B. Hoover, D. Irons, N. Jones, K. J. Kuletz, C. A. Nordstrom, R. Paredes, and R. M. Suryan. 2013. Prey patch patterns predict habitat use by top marine predators with diverse foraging strategies. PLoS ONE 8:e53348.

Bigelow, K. A., C. H. Boggs, and X. He. 1999. Environmental effects on swordfish and blue shark catch rates in the US North Pacific longline fishery. Fisheries Oceanography 8: 178-198.

Bost, C., et al. 2015. Large-scale climatic anomalies affect marine predator foraging behaviour and demography. Nature Communications 6:8220 doi: $10.1038 /$ ncomms 9220

Bouchet, P. J., J. J. Meeuwig, S. Kent, P. Chandra, T. B. Letessier, and C. K. Jenner. 2015. Topographic determinants of mobile vertebrate predator hotspots: current knowledge and future directions. Biological Reviews 90:699-728.

Broquet, G., C. Edwards, A. Moore, B. Powell, M. Veneziani, and J. Doyle. 2009. Application of 4D-variational data assimilation to the California current system. Dynamics of Atmospheres and Oceans 48:69-92.
Costa, D. P., and B. Sinervo. 2004. Field physiology: physiological insights from animals in nature. Annual Review of Physiology 66:209-238.

Cotté, C., F. d'Ovidio, A.-C. Dragon, C. Guinet, and M. Lévy. 2015. Flexible preference of southern elephant seals for distinct mesoscale features within the Antarctic Circumpolar Current. Progress in Oceanography 131:46-58.

da Rocha Fragoso, M., G. V. de Carvalho, F. L. M. Soares, D. G. Faller, L. P. de Freitas Assad, R. Toste, L. M. B. Sancho, E. N. Passos, C. S. Böck, and B. Reis. 2016. A 4Dvariational ocean data assimilation application for Santos Basin, Brazil. Ocean Dynamics 66:419-434.

De'Ath, G. 2007. Boosted trees for ecological modelling and prediction. Ecology 88:243-251.

Dewar, H., E. D. Prince, M. K. Musyl, R. W. Brill, C. Sepulveda, J. Luo, D. Foley, E. S. Orbesen, M. L. Domeier, and N. Nasby-Lucas. 2011. Movements and behaviors of swordfish in the Atlantic and Pacific Oceans examined using popup satellite archival tags. Fisheries Oceanography 20:219-241.

Dunn, D. C., S. M. Maxwell, A. M. Boustany, and P. N. Halpin. 2016. Dynamic ocean management increases the efficiency and efficacy of fisheries management. Proceedings of the National Academy of Sciences 113(3):668-673.

Elith, J., and J. R. Leathwick. 2009. Species distribution models: ecological explanation and prediction across space and time. Annual Review of Ecology, Evolution, and Systematics 40:677.

Elith, J., J. R. Leathwick, and T. Hastie. 2008. A working guide to boosted regression trees. Journal of Animal Ecology 77: 802-813.

Evans, K., F. Abascal, D. Kolody, T. Sippel, J. Holdsworth, and P. Maru. 2014. The horizontal and vertical dynamics of swordfish in the South Pacific Ocean. Journal of Experimental Marine Biology and Ecology 450:55-67.

Fiechter, J., L. A. Huckstadt, K. A. Rose, and D. P. Costa. 2016. A fully coupled ecosystem model to predict the foraging ecology of apex predators in the California Current. Marine Ecology Progress Series 556:273-285.

Fiechter, J., K. A. Rose, E. N. Curchitser, and K. S. Hedstrom. 2014. The role of environmental controls in determining sardine and anchovy population cycles in the California Current: analysis of an end-to-end model. Progress in Oceanography 138:381-398.

Fossette, S., M. Witt, P. Miller, M. Nalovic, D. Albareda, A. Almeida, A. Broderick, D. Chacón-Chaverri, M. Coyne, and A. Domingo. 2014. Pan-Atlantic analysis of the overlap of a highly migratory species, the leatherback turtle, with pelagic longline fisheries. Proceedings of the Royal Society B 281:20133065.

Gutknecht, E., I. Dadou, B. Le Vu, G. Cambon, J. Sudre, V. Garçon, E. Machu, T. Rixen, A. Kock, and A. Flohr. 2013. Coupled physical/biogeochemical modelling including O-2dependent processes in the Eastern Boundary Upwelling Systems: application in the Benguela. Biogeosciences 10:3559-3591.

Guy, T. J., S. Jennings, R. Suryan, E. Melvin, M. A. Bellman, L. Ballance, B. Blackie, D. Croll, T. Deguchi, and T. Geernaert. 2013. Overlap of North Pacific albatrosses with the US west coast groundfish and shrimp fisheries. Fisheries Research 147:222-234

Hazen, E. L., S. Jorgensen, R. R. Rykaczewski, S. J. Bograd, D. G. Foley, I. D. Jonsen, S. A. Shaffer, J. P. Dunne, D. P. Costa, and L. B. Crowder. 2013b. Predicted habitat shifts of Pacific top predators in a changing climate. Nature Climate Change 3:234-238.

Hazen, E. L., R. M. Suryan, J. A. Santora, S. J. Bograd, Y. Watanuki, and R. P. Wilson. 2013a. Scales and mechanisms of marine hotspot formation. Marine Ecology Progress series 487:177-183. 
Hazen, E. L., et al. 2016. WhaleWatch: a dynamic management tool for predicting blue whale density in the California Current. Journal of Applied Ecology doi:10.1111/1365-2664.12820

Hijmans, R. J., and van Etten J. 2012. raster: Geographic analysis and modeling with raster data. $\mathrm{R}$ package version 2.0-12. http://CRAN.R-project.org/package=raster

Hobday, A. J., and J. R. Hartog. 2014. Derived ocean features for dynamic ocean management. Oceanography 27:134-145.

Hobday, A. J., J. R. Hartog, C. M. Spillman, O. Alves, and R. Hilborn. 2011. Seasonal forecasting of tuna habitat for dynamic spatial management. Canadian Journal of Fisheries and Aquatic Sciences 68:898-911.

Hobday, A. J., S. M. Maxwell, J. Forgie, and J. McDonald. 2013. Dynamic ocean management: integrating scientific and technological capacity with law, policy, and management. Stanford Environmental Law Journal 33:125.

Hsu, A. C., A. M. Boustany, J. J. Roberts, J. H. Chang, and P. N. Halpin. 2015. Tuna and swordfish catch in the US northwest Atlantic longline fishery in relation to mesoscale eddies. Fisheries Oceanography 24:508-520.

Kahru, M., R. M. Kudela, M. Manzano-Sarabia, and B. G. Mitchell. 2012. Trends in the surface chlorophyll of the California Current: merging data from multiple ocean color satellites. Deep Sea Research Part II: Topical Studies in Oceanography 77:89-98.

Kaplan, I. C., G. D. Williams, N. A. Bond, A. J. Hermann, and S. A. Siedlecki. 2016. Cloudy with a chance of sardines: forecasting sardine distributions using regional climate models. Fisheries Oceanography 25:15-27.

Koné, V., C. Lett, and P. Fréon. 2013. Modelling the effect of food availability on recruitment success of Cape anchovy ichthyoplankton in the southern Benguela upwelling system. African Journal of Marine Science 35:151-161.

Lazaridis, E. 2014. Lunar: lunar phase \& distance, seasons and other environmental factors (version 0.1-04). http://statistics. lazaridis.eu

Leathwick, J., J. Elith, M. Francis, T. Hastie, and P. Taylor. 2006. Variation in demersal fish species richness in the oceans surrounding New Zealand: an analysis using boosted regression trees. Marine Ecology Progress Series 321:267-281.

Lewison, R., et al. 2015. Dynamic ocean management: identifying the critical ingredients of dynamic approaches to ocean resource management. BioScience 65:486-498.

Luo, Y., K. Ogle, C. Tucker, S. Fei, C. Gao, S. LaDeau, J. S. Clark, and D. S. Schimel. 2011. Ecological forecasting and data assimilation in a data-rich era. Ecological Applications 21:1429-1442.

Markaida, U., and F. Hochberg. 2005. Cephalopods in the diet of swordfish (Xiphias gladius) caught off the west coast of Baja California, Mexico 1. Pacific Science 59:25-41.

Martin, S. L., S. M. Stohs, and J. E. Moore. 2015. Bayesian inference and assessment for rare-event bycatch in marine fisheries: a drift gillnet fishery case study. Ecological Applications 25:416-429.

Maxwell, S. M., E. L. Hazen, S. J. Bograd, B. S. Halpern, G. A. Breed, B. Nickel, N. M. Teutschel, L. B. Crowder, S. Benson, and P. H. Dutton. 2013. Cumulative human impacts on marine predators. Nature Communications 4. https://doi.org/ 10.1038/ncomms 3688

Maxwell, S. M., E. L. Hazen, R. L. Lewison, D. C. Dunn, H. Bailey, S. J. Bograd, D. K. Briscoe, S. Fossette, A. J. Hobday, and M. Bennett. 2015. Dynamic ocean management: defining and conceptualizing real-time management of the ocean. Marine Policy 58:42-50.

McGowan, J., E. Hines, M. Elliott, J. Howar, A. Dransfield, N. Nur, and J. Jahncke. 2013. Using seabird habitat modelling to inform marine spatial planning in central California's National Marine Sanctuaries. PLoS ONE 8:e71406.

Metcalfe, K., T. Collins, K. E. Abernethy, R. Boumba, J. C. Dengui, R. Miyalou, R. J. Parnell, K. E. Plummer, D. J. Russell, and G. K. Safou. 2016. Addressing uncertainty in marine resource management; combining community engagement and tracking technology to characterise human behaviour. Conservation Letters. https://doi.org/10.1111/conl.12293. In Press.

Michener, W. K., and M. B. Jones. 2012. Ecoinformatics: supporting ecology as a data-intensive science. Trends in Ecology \& Evolution 27:85-93.

Morato, T., S. D. Hoyle, V. Allain, and S. J. Nicol. 2010. Seamounts are hotspots of pelagic biodiversity in the open ocean. Proceedings of the National Academy of Sciences USA 107:9707-9711.

Neveu, E., A. M. Moore, C. A. Edwards, J. Fiechter, P. Drake, W. J. Crawford, M. G. Jacox, and E. Nuss. 2016. An historical analysis of the California Current circulation using ROMS 4D-Var: system configuration and diagnostics. Ocean Modelling 99:133-151.

Penven, P., C. Roy, G. Brundrit, A. C. De Verdière, P. Fréon, A. Johnson, J. Lutjeharms, and F. Shillington. 2001. A regional hydrodynamic model of upwelling in the Southern Benguela. South African Journal of Science 97:472-475.

Podestá, G. P., J. A. Browder, and J. J. Hoey. 1993. Exploring the association between swordfish catch rates and thermal fronts on US longline grounds in the western North Atlantic. Continental Shelf Research 13:253-277.

Pollock, L. J., R. Tingley, W. K. Morris, N. Golding, R. B. O'Hara, K. M. Parris, P. A. Vesk, and M. A. McCarthy. 2014. Understanding co-occurrence by modelling species simultaneously with a Joint Species Distribution Model (JSDM). Methods in Ecology and Evolution 5:397-406.

Queiroz, N., N. E. Humphries, G. Mucientes, N. Hammerschlag, F. P. Lima, K. L. Scales, P. I. Miller, L. L. Sousa, R. Seabra, and D. W. Sims. 2016. Ocean-wide tracking of pelagic sharks reveals extent of overlap with longline fishing hotspots. Proceedings of the National Academy of Sciences USA 113:1582-1587.

R Core Team. 2013. R: a language and environment for statistical computing. R Foundation for Statistical Computing, Vienna, Austria. http://www.R-project.org/

Raymond, B., M. A. Lea, T. Patterson, V. Andrews-Goff, R. Sharples, J. B. Charrassin, M. Cottin, L. Emmerson, N. Gales, and R. Gales. 2015. Important marine habitat off east Antarctica revealed by two decades of multi-species predator tracking. Ecography 38:121-129.

Rose, K. A., J. Fiechter, E. N. Curchitser, K. Hedstrom, M. Bernal, S. Creekmore, A. Haynie, S.-I. Ito, S. Lluch-Cota, and B. A. Megrey. 2015. Demonstration of a fully-coupled end-toend model for small pelagic fish using sardine and anchovy in the California Current. Progress in Oceanography 138:348-380.

Rousseaux, C., T. Hirata, and W. Gregg. 2013. Satellite views of global phytoplankton community distributions using an empirical algorithm and a numerical model. Biogeosciences Discussions 10:1083-1109.

Scales, K. L., P. I. Miller, C. B. Embling, S. N. Ingram, E. Pirotta, and S. C. Votier. 2014. Mesoscale fronts as foraging habitats: composite front mapping reveals oceanographic drivers of habitat use for a pelagic seabird. Journal of the Royal Society Interface 11:20140679.

Scott, B., A. Webb, M. Palmer, C. Embling, and J. Sharples. 2013. Fine scale bio-physical oceanographic characteristics predict the foraging occurrence of contrasting seabird species; Gannet (Morus bassanus) and storm petrel (Hydrobates pelagicus). Progress in Oceanography 117:118-129. 
Seki, M. P., J. J. Polovina, D. R. Kobayashi, R. R. Bidigare, and G. T. Mitchum. 2002. An oceanographic characterization of swordfish (Xiphias gladius) longline fishing grounds in the springtime subtropical North Pacific. Fisheries Oceanography 11:251-266.

Sepulveda, C. A., A. Knight, N. Nasby-Lucas, and M. L. Domeier. 2010. Fine-scale movements of the swordfish Xiphias gladius in the Southern California Bight. Fisheries Oceanography 19:279-289.

Sequeira, A. M., C. Mellin, H. M. Lozano-Montes, M. A. Vanderklift, R. C. Babcock, M. D. Haywood, J. J. Meeuwig, and M. J. Caley. 2016. Transferability of predictive models of coral reef fish species richness. Journal of Applied Ecology 53:64-72.

Shchepetkin, A. F., and J. C. McWilliams. 2005. The regional oceanic modelling system (ROMS): a split-explicit, free-surface, topography-following-coordinate oceanic model. Ocean Modelling 9:347-404.

Siedlecki, S. A., I. C. Kaplan, A. J. Hermann, T. T. Nguyen, N. A. Bond, J. A. Newton, G. D. Williams, W. T. Peterson, S. R. Alin, and R. A. Feely. 2016. Experiments with Seasonal Forecasts of ocean conditions for the Northern region of the California Current upwelling system. Scientific Reports 6.

Song, H., C. A. Edwards, A. M. Moore, and J. Fiechter. 2016. Data assimilation in a coupled physical-biogeochemical model of the California current system using an incremental lognormal 4-dimensional variational approach: Part 3Assimilation in a realistic context using satellite and in situ observations. Ocean Modelling 106:159-172.

Soykan, C. U., T. Eguchi, S. Kohin, and H. Dewar. 2014. Prediction of fishing effort distributions using boosted regression trees. Ecological Applications 24:71-83.

Torres, L. G., P. J. Sutton, D. R. Thompson, K. Delord, H. Weimerskirch, P. M. Sagar, E. Sommer, B. J. Dilley, P. G. Ryan, and R. A. Phillips. 2015. Poor transferability of species distribution models for a pelagic predator, the grey petrel, indicates contrasting habitat preferences across ocean basins. PLOS ONE 10:e0120014.

Young, J., A. Hobday, R. Campbell, R. Kloser, P. Bonham, L. Clementson, and M. Lansdell. 2011. The biological oceanography of the East Australian Current and surrounding waters in relation to tuna and billfish catches off eastern Australia. Deep Sea Research Part II: Topical Studies in Oceanography 58:720-733.

Young, J., M. Lansdell, S. Riddoch, and A. Revill. 2006. Feeding ecology of broadbill swordfish, Xiphias gladius, off eastern Australia in relation to physical and environmental variables. Bulletin of Marine Science 79:793-809.

\section{SUPPORTING INFORMATION}

Additional supporting information may be found online at: http://onlinelibrary.wiley.com/doi/10.1002/eap.1610/full

\section{Data Availability}

Data available from figshare: https://doi.org/10.6084/m9.figshare.5266543. Regional Ocean Modelling System (ROMS) products for the California Current System available at: http://oceanmodelling.ucsc.edu/ccsnrt. Fisheries data collected by the NOAA Southwest Fisheries Observer Program available at: http://www.westcoast.fisheries.noaa.gov/fisheries/wc_observer_programs/sw_ observer_program_info/data_summ_report_sw_observer_fish.html 